J. Amer. Soc. Hort. ScI. 118(1):145-150. 1993.

\title{
Orange Flesh Trait in Potato: Inheritance and Carotenoid Content
}

\author{
C.R. Brown ${ }^{1}$, C.G. Edwards ${ }^{2}$, C.-P. Yang ${ }^{3}$, B.B. Dean ${ }^{4}$ \\ U.S. Department of Agriculture-Agricultural Research Service and Washington State University-irrigated \\ Agriculture Research and Extension Center, Route 2 Box 2953A, Prosser, WA 99350
}

Additional index words. Breeding, Solanum, xanthophyll, zeaxanthin

\begin{abstract}
Potatoes with orange flesh were found in cultivated diploid $(2 \mathrm{n}=24)$ potato populations derived from Solanum stenotomum Juz. et Buk. and S.phureja Juz. et Buk. The orange flesh trait was found to be controlled by an allele at the $Y$ locus designated Or. Or is dominant over $Y$ and y, which control yellow and white flesh, respectively. In a comparison of white and orange flesh segregants from crosses, the orange was associated with large amounts of zeaxanthin, a xanthophyll previously not reported as a constituent of potato flesh carotenoids. The combined total of lutein and zeaxanthin was four times higher than the highest carotenoid composition previously reported for potato, this is about one-sixth the total carotenoid content of carrot with standard carotenoid levels, although lutein and zeaxanthin do not possess provitamin A activity.
\end{abstract}

Germplasm of potato exists in the form of eight taxonomic cultivated species and in $>200$ wild species that can be found in various world collections and in native habitats. This large reservoir of genetic variation can provide useful new traits for potato variety development (Hanneman and Bamberg, 1986). The cultivated species, although ranging in ploidy from diploid, $2 \mathrm{n}=24$, to pentaploid, $2 n=60$, are intercrossable within ploidy levels, and, if appropriate ploidy manipulations are performed, crosses can be made between ploidy levels. Geneticvariation in diploid cultivated potato is easily incorporated into tetraploid varieties (Peloquin, 1982). New variation from exotic germplasm must first be characterized phenotypically and genetically for efficient use in breeding to take place.

Tuber flesh color is determined by the presence of two classes of compounds. Anthocyanin pigments impart red, blue, and purple flesh colors, whereas carotenoids, predominantly xanthophylls, produce yellow flesh color (Howard, 1970; Iwanzik et al., 1983; Tevini et al., 1984). Yellow pigmentation has been shown to be controlled by a single gene with the yellow flesh state dominant over the white flesh state (Fruwirth, 1912). Modifying genes may also be important (Schick, 1956). The yellow flesh locus, $Y$, has been mapped to chromosome 3 (Bonierbale et al., 1988). Yellow flesh potato varieties are preferred on the European continent (Siebenick, 1959). Caldwell et al. (1945) reported that the range of total carotenoid content of 22 white-fleshed varieties and breeding clones lay between 14 and $187 \mu \mathrm{g} / 100 \mathrm{~g}$ fresh weight. Brunstetter and Wiseman (1947) observed the total carotenoid content of white flesh 'Katahdin' to be 300 pg/100 g. Iwanzik et al. (1983) found that the sum of the xanthophylls in yellow flesh European varieties ranged from 27 to $342 \mu \mathrm{g} / 100 \mathrm{~g}$. Pendlington et al. (1965) identified beta-carotene and seven xanthophylls, including epoxides and nonepoxides in white-fleshed varieties. Although Iwanzik et

Rcceived for publication 2 Dec. 1991. Accepted for publication 15 Aug. 1992. Hoffman-La Roche kindly contributed samples of pure zeaxanthin for this research. Kevin O'Connor of Waters, Inc., provided invaluable guidance and technical support for the HPLC analysis of these materials. The cost of publishing this paper was defrayed in part by the payment of page charges. Under postal regulations, this paper therefore must be hereby marked advertisement solely to indicate this fact.

${ }^{1}$ Research Geneticist.

${ }^{2}$ Assistant Food Scientist.

${ }^{3}$ Biological Technician.

${ }^{4}$ Associate Horticulturist. al. (1983) detected beta-carotene in trace amounts in yellow flesh potato, the xanthophylls lutein and violaxanthin accounted for nearly all the carotenoid content.

Potatoes with orange flesh were discovered in cultivated diploid breeding populations in the present study. Since this type of variation had not previously been reported, research was undertaken to determine the relationship between orange color and carotenoid constituents. Content of certain carotenoids was determined, and comparisons of carotenoids in orange and white flesh segregants were made. In addition, $\mathrm{F}_{1}$ and $\mathrm{BC}_{1}$ crosses were made, and the tubers of progeny were scored to determine the inheritance of orange flesh.

\section{Materials and Methods}

Provenance ofgenetic materials. Botanical seed of populations derived from plant introductions of diploid cultivated species Solanum phureja and S. stenotomum and the clone DM56.4 were obtained from Frank Haynes, formerly of the Dept. of Horticulture, North Carolina State Univ., Raleigh. The orange flesh type was noted in segregating families of two half-sib accessions (85D4 and 85D6). Two orange flesh clones, a clone selected from 85D6, designated D6.11, and DM56.4, were crossed with each other and with parents having white and yellow flesh types. The clone W5337.3 is a yellow flesh type provided by S.J. Peloquin, Dept. of Horticulture, Univ. of Wisconsin, Madison. W5337.3 is a hybrid between a haploid $(2 \mathrm{n}=2 \mathrm{x}=24)$ of tetraploid cv. Chippewa and S. phureja. The clone BC160 is a white flesh Solanum chacoense Bitt., resistant to potato leafroll virus, selected from PI 133124 of IR-1, Inter-Regional Potato Introduction Project, Sturgeon Bay, Wis. The white flesh cultivated tetraploid clone, A7411.2, was obtained from J. Pavek, U.S. Dept. of Agriculture, Agricultural Research Service, Aberdeen, Idaho. Sweetpotato [Ipomoea batatas (L.) Lam.] was purchased at a local supermarket.

Crossing and genetic analysis. Flowers of pistillate parents were emasculated 2 days before anthesis. Pollen was vibrated from staminate parent flowers into gelatin capsules and stored in sealed containers with activated silica gel. Pollen was used on the day of extraction and sometimes on two successive days while being stored in the interim at $-12 \mathrm{C}$. Pollen was applied to stigmas of fully opened emasculated flowers by inserting the style into the gelatin capsule so that pollen coated the stigma. Seeds were squeezed from ripe fruits into water, air dried on paper towels, and then soaked for 


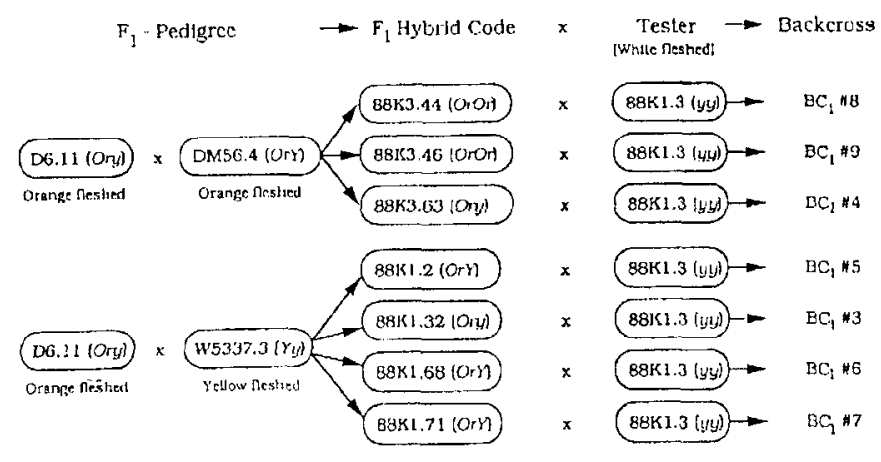

Fig. 1. Scheme of crosses resulting in $F_{1}$ hybrids and $B C_{1}$ segregants.

$24 \mathrm{~h}$ in $1500 \mathrm{ppm}$ gibberellic acid solution before being sown.

Orange flesh clone D6.11 was crossed with yellow flesh W5337.3 and with orange flesh DM56.4 to produce $F_{1}$ progenies (Fig. 1). Since cultivated diploid potatoes have a gametophytic self-incompatibility, it is often difficult or impossible to obtain $F_{2}$ progeny. Backcrosses to a recurrent parent are often unsuccessful due to sharing of S-alleles (Howard, 1970). Orange fleshed $F_{1}$ progenies (e.g., 88K3.44, 88K1.2, etc.) werecrossed to a single $\mathrm{F}_{1}$ white flesh tester (88K1.3), which proved to be a compatible crossing partner with all orange-fleshed clones attempted. The backcross progenies resulting from these crosses were numbered \#3 through \#9 in Fig. 1 and Table 2. Yellow flesh W5337.3 was crossed with white flesh BC160. Plants were grown in the field during the summer using standard practices (222 kg N/ha preplant) at Bickleton, Wash., harvested in mid-September, placed in storage at $4 \mathrm{C}$ and $80 \%$ relative humidity in light-excluding cardboard boxes, and kept 4 months before scoring of flesh color. Tubers used in the quantitation study were grown in pots from February to April in a greenhouse $\left(15,000\right.$ photosynthetic photon flux density $\mu \mathrm{mol}$ photons $/ \mathrm{m}^{2}$ per sec) and then in a screen house for the last 2 months of growth before harvest on 6 June. Flesh color was scored by cutting freshly harvested tubers and measuring $L^{*} a^{*} b^{*}$ values using a Minolta Chroma Meter CR-200. L* $a^{*} b^{*}$ values were determined by taking three measurements at random locations on freshly cut surfaces of three separate tubers (nine measurements total).

Extraction method I-Hydrocarbon carotenes. Method I extraction procedure to analyze hydrocarbon carotenes was adapted from Singh and Bradbury (1988) and O'Connor (1990). Fresh tuber samples were freeze dried, ground into powder, and homogenized in a polytron with acetone (J.T. Baker, Phillipsburg, N.J., reagent grade). The slurry was filtered through a $10-\mathrm{cm}$ Buchner funnel containing Whatman filter \#1 paper. The extraction procedure was repeated until the filtrate was colorless. Acetone filtrates were combined and extracted with 150-ml aliquots of hexane (J.T. Baker, reagent grade) in a separatory funnel until the hexane layer was colorless. Hexane extracts were combined and washed with water before evaporation to dryness using a rotary evaporator (30C). Saponification was carried out by adding $40 \% \mathrm{KOH} /$ methanol (w/v) to the dried extract and holding for $24 \mathrm{~h}$ at $21 \mathrm{C}$ under $\mathrm{N}_{2}$ gas. The $\mathrm{KOH} /$ methanol solution was poured into a separatory funnel and the carotenoids extracted with hexane until colorless. Hexane extracts were combined and washed with deionized water six to seven times until the aqueous fraction was $\mathrm{pH}$ neutral. The hexane extract was passed through a glass funnel packed with sodium sulfate for dehydration, evaporated to dryness using a rotary evaporator, and redissolved in a minimal volume of toluene (Burdick and Jackson, Muskegon, Mich., HPLC grade). Extracts were passed through Millipore $0.5 \mu \mathrm{m}$ Millex LCR4 filters to remove debris before HPLC analysis.

Extraction method II-Xanthophylls. The extraction procedure was taken in varying parts from Iwanzik et al. (1983), Singh and Bradbury (1988), and O'Connor (1990). Fresh unpeeled tubers (100 g; mean weight of tubers $20 \mathrm{~g}$ ) were washed, patted dry with paper towels, and cut into $1-\mathrm{cm}^{3}$ pieces before transfer to a Waring blender containing $100 \mathrm{ml}$ of acetone with $300 \mathrm{mg}$ of granular ascorbic acid added. The internal standard, trans-Beta-Apo-8'carotenal (Fluka, Switzerland) was added to achieve a concentration of $0.025 \mu \mathrm{g} \cdot \mu^{-1}$ of the final extract volumes $(2 \mathrm{ml}$ for yellow and white flesh extracts and $5 \mathrm{ml}$ for orange flesh extracts). Tubers were homogenized for $1 \mathrm{~min}$ and filtered through a 10-cm Buchner funnel containing Whatman \#1 filterpaper. Extraction wasrepeated until the filtrates were colorless. The combined filtrates were transferred into a 1000-ml separatory funnel and repeatedly extracted using 75-ml portions of hexane. The hexane extracts were combined and dried at $30 \mathrm{C}$ using a rotary evaporator. The residue was dissolved in a minimum of hexane and dehydrated over sodium sulfate followed by rotary evaporation. The xanthophylls were redissolved in 2- to 5-ml acetone (J.T. Baker, reagent grade) and passed through Millipore 0.5- $\mu$ m Millex LCR4 filters.

Identification and quantitation of carotenoids. Reverse-phase HPLC separation of the carotenoids was accomplished using a Waters HPLC system (Waters, Milford, Mass.) equipped with a Model 710 WISP automaticinjector, Model 490E multiwavelength detector set at $450 \mathrm{~nm}$, and a Nova-Pak $\mathrm{C}_{18}, 4 \mu \mathrm{m}$ packing, $3.9 \times 300$ $\mathrm{mm}$ column. Chromatographic peaks were integrated (microvoltset) with the Maxima 820 program. For carotenoids extracted using method I, chromatographic separation was accomplished using a single mobile phase consisting of 5.8 acetonitrile : 3.5 methanol : 0.7 tetrahydrofuran (O'Connor, 1990). The hexane extract was evaporated to dryness and redissolved in a minimal amount of toluene to make a final concentration of one part toluene to three parts mobile phase. A sample of $10 \mu \mathrm{l}$ was injected. HPLC analysis of extract obtained by method II was adapted from Rivas et al. (1989). The method consisted of three solvents run isocratically and sequentially: solvent A (0 to $6 \mathrm{~min}) ; 7.0$ acetonitrile : 0.96 methanol : 0.04 water); solvent $\mathrm{B}$ (6 to $15 \mathrm{~min}$ ); 7.0 acetonitrile : 0.96 methanol : 0.04 water : 2.0 ethyl acetate; solvent $\mathrm{C}$ (1.5 to 20 min); 7.0 acetonitrile : 0.96 methanol : 0.04 water : 8.0 ethyl acetate. After solvent $\mathrm{C}$, solvent $\mathrm{A}$ was run through the column for $15 \mathrm{~min}$ to recondition the column. HPLC separations were run at 20 to $22 \mathrm{C}$ and $1.0 \mathrm{ml} \cdot \mathrm{min}^{-1}$ flow rate. All organic solvents used in the mobile phases were HPLC grade (Burdick and Jackson).

Identification of the carotenoids was performed by collecting peaks eluting from the HPLC, dissolving them separately in chloroform, hexane, and ethanol, and determining spectral absorbance maxima characteristics using a Shimadzu Model UV160 U spectrophotometer (Shimadzu, Kyoto, Japan). Spectral characteristics were compared to those published by Bauernfeind (1981) and De Ritter and Purcell (1981). Retention times of samples of pure zeaxanthin (Hoffman-La Roche, Belvedere, N.J.) lutein (Sigma, St. Louis), and beta-carotene (Sigma) were also used to assist in identification.

\section{Results}

Color. The values of $\mathrm{a}^{*}$ and $\mathrm{b}^{*}$ define color on a two dimensional chromatic space, $\mathrm{a}^{*}$ and $\mathrm{b}^{*}$ indicating the green-red and blue-yellow axes, respectively, while $\mathrm{L}^{*}$ is a measure of lightness (Hunter, 1942). The three flesh type colors are clearly distinguishable and show very little variation as evidenced by the small standard errors associated with the means (Table 1). Largest 
Table 1. Color measurements ${ }^{\mathrm{z}}$ of white, yellow, and orange fleshed potatoes in $\mathrm{L}^{*} \mathrm{a}^{*} \mathrm{~b}^{*}$ chromatic space.

\begin{tabular}{lcccc}
\hline \hline & & \multicolumn{3}{c}{ Hunter values } \\
\cline { 3 - 5 } Flesh type & Clone & $\mathrm{L}^{*}$ & \multicolumn{1}{c}{$\mathrm{a}^{*}$} & $\mathrm{~b}^{*}$ \\
\hline White & A7411.2 & $70.4 \pm 0.45$ & $-1.50 \pm 0.07$ & $14.7 \pm 0.10$ \\
Yellow & W5335.7 & $66.4 \pm 0.65$ & $-4.52 \pm 0.60$ & $35.0 \pm 0.63$ \\
Orange & D6.11 & $75.0 \pm 0.20$ & $0.51 \pm 0.13$ & $53.8 \pm 0.56$
\end{tabular}

${ }^{\mathrm{z}}$ Mean and SE of nine measurements.

differences were observed for $b^{*}$, where values ranged from 15 for white, 35 for yellow, and 54 for orange flesh. The maximum b* values reported by Iwanzik et al. (1983) were 22,28, and 32 for white, yellow, and intense-yellow flesh colors in 13 European varieties; values were considerably lower than those observed for the orange flesh clones dealt with in this study.

Inheritance of orange flesh trait. The orange phenotype was noted initially in two diploid open-pollinated half-sib families derived from a population of $S$. phureja $\times S$. stenotomum intercrosses recurrently selected for tolerance to long photoperiod and heat. Phenotypic frequencies of flesh color were scored visually (Table 2). In 85D4 orange, yellow, and white phenotypes constituted $31.3,60.3$, and $2.4 \%$, whereas in 85D6 these flesh types occurred with frequencies of $21.3,76.8$, and $1.8 \%$. These results indicate that the mother plants from which these seedlots were obtained likely were $Y y$ genotypes, and the pollen pool had gene frequency of orange factors between 0.2 and 0.3 .

Two $\mathrm{F}$, crosses and a series of $\mathrm{BC}_{1}$ crosses to a common white flesh recurrent parent were performed. The pedigrees of the crosses are shown in Fig. 1, while segregation of flesh colors is shown in Table 2. Upon examination of $\mathrm{F}_{1}$ and $\mathrm{BC}_{1}$ crosses, several hypotheses may be tested. We already have noted above that the yellow flesh phenotype is controlled by a single gene that is dominant over white flesh, and this is corroborated by cross $\mathrm{F}_{1} \# 2$ (Table 2). Backcrosses $\mathrm{BC}_{1} \# 3$ and $\mathrm{BC}_{1} \# 4$ support a single gene hypothesis for the control of orange vs. white flesh, presenting a $1: 1$ segregation of progeny from crosses of orange with white parents.

The relationship of the yellow vs. orange state is elucidated by segregation of $F_{1} \# 1$ (Table 2). Progeny from the cross of the orange D6.11 by the yellow W5337.3 parents resulted in segregation of 2 orange : 1 yellow : 1 white. This result is consistent with single gene control of orange flesh, dominance of orange flesh over yellow flesh, and dominance of yellow flesh over white flesh.

A test of allelism of orange and yellow can be extracted from segregation ratios in backcrosses $\mathrm{BC}_{1} \# 5, \mathrm{BC}_{1} \# 6$, and $\mathrm{BC}_{1} \# 7$ (Table 2 ). The orange parents in these three crosses arose from a cross between heterozygous yellow and heterozygous orange parents, W5337.3 and D6.11, respectively. The progeny contains orange and yellow flesh progenies yet no white flesh ones. These data negate the hypothesis of an independent orange locus. Two hypotheses remain: 1) allelism, or 2) close linkage. The data are consistent with the orange state being controlled by an allele coding for orange flesh at the Y locus. If an orange allele is postulated, denoted $O r$, the orange parents in these three crosses would be genotypically $\operatorname{OrY}$, yielding Ory (orange flesh) and $Y y$ (yellow flesh) progenies in equal numbers. The orange and yellow flesh possibly are controlled by separate but closely linked genes in repulsion phase. Larger progeny sizes would be necessary to exclude this option with a high confidence level. From the progeny test results, $88 \mathrm{~K} 1.32$ was Ory, while $88 \mathrm{~K} 1.2$, $88 \mathrm{~K} 1.68$, and $88 \mathrm{~K} 1.71$ were $\operatorname{OrY}$.

The cross D6.11 $\times$ DM56.4 is between two orange phenotypes. Assuming that $\mathrm{Or}$ is an allele at the Y-locus, genotype $\mathrm{Or} Y$ may be assigned to DM56.4 and Ory to D6.11, as determined above. Orange flesh progenies from this cross could be $\mathrm{OrOr}$, OrY, or Ory. Clones $88 \mathrm{~K} 3.44$ and $88 \mathrm{~K} 3.46$ were identified as $\mathrm{OrOr}$, as all of their backcross progeny were orange (see $\mathrm{BC}_{1} \# 8$ and $\mathrm{BC}_{1} \# 9$, Table 2 ). In contrast, backcross progeny derived from $88 \mathrm{~K} 1.32$ and 88K3.63 segregated 1:1 for orange and white flesh progeny, permitting attribution of genotype Ory, due to its 1:1 segregation of white and orange phenotypes $\left(\mathrm{BC}_{1} \# 3\right.$ and $\left.\mathrm{BC}_{1} \# 4\right)$.

Identification of carotenoids. Although large amounts of a carotene corresponding to the retention time of the beta-carotene standard were detected in sweetpotato using extraction method I, no such peaks were found in orange flesh potato $88 \mathrm{~K} 1.2$ (results not shown). Additional chromatographic peaks were observed. Further analysis focused on method II, designed for analysis of xanthophylls. Table 3 presents the absorbance maxima obtained from scanning the collected fractions of the three major component peaks that were present in the materials segregating for white and yellow flesh. Lutein and zeaxanthin were identified by reference to published tables for the three solvents and co-elution with pure standards. Identification of a third peakcould not be confirmed, but spectra were close to those of citroxanthin or mutatochrome. The fraction identified as zeaxanthin was orange-red, while all other fractions were yellow in all solvents.

Table 2. Segregation of orange, yellow, and white flesh types in stored tubers of diverse crosses. Data test the hypothesis that orange flesh is controlled by allele $O r$ at $Y$-locus, which is dominant to $Y$ and $y$ alleles.

\begin{tabular}{|c|c|c|c|c|c|c|c|c|}
\hline \multirow[b]{2}{*}{ Cross } & \multirow[b]{2}{*}{ Code } & \multirow[b]{2}{*}{ Genotype } & \multicolumn{3}{|c|}{ Phenotype } & \multirow[b]{2}{*}{ Hypothesis } & \multirow[b]{2}{*}{$\mathrm{X}^{2}$} & \multirow[b]{2}{*}{$P$} \\
\hline & & & Orange & Yellow & White & & & \\
\hline D6.11 x W5337.3 & $\mathrm{F}_{1} \# 1$ & Ory $\times Y y$ & 35 & 20 & 20 & $2: 1: 1$ & 0.167 & $0.9<P<0.975$ \\
\hline BC160 x W5337.3 & $\mathrm{F}_{1} \# 2$ & $y y \times Y y$ & & 23 & 21 & $0: 1: 1$ & 0.023 & $0.5<P<0.9$ \\
\hline $88 \mathrm{~K} 1.32 \times 88 \mathrm{~K} 1.3$ & $\mathrm{BC}_{1} \# 3$ & Ory $x y y$ & 19 & & 24 & $1: 0: 1$ & 0.372 & $0.5<P<0.9$ \\
\hline $88 \mathrm{~K} 3.63 \times 88 \mathrm{~K} 1.3$ & $\mathrm{BC}_{1} \# 4$ & Ory $x y y$ & 29 & & 29 & $1: 0: 1$ & 0 & -.- \\
\hline $88 \mathrm{~K} 1.2 \times 88 \mathrm{~K} 1.3$ & $\mathrm{BC}_{1} \# 5$ & $O r Y \times y y$ & 14 & 18 & & $1: 1: 0$ & 0.281 & $0.5<P<0.9$ \\
\hline $88 \mathrm{~K} 1.68 \times 88 \mathrm{~K} 1.3$ & $\mathrm{BC}_{1} \# 6$ & $O r Y \times y y$ & 13 & 12 & & $1: 1: 0$ & 0 & -.- \\
\hline $88 \mathrm{~K} 1.71 \times 88 \mathrm{~K} 1.3$ & $\mathrm{BC}_{1} \# 7$ & $O r Y \times y y$ & 15 & 18 & & $1: 1: 0$ & 0.121 & $0.5<P<0.9$ \\
\hline $88 \mathrm{~K} 3.44 \times 88 \mathrm{~K} 1.3$ & $\mathrm{BC}_{1} \# 8$ & OrOr $\times y y$ & 47 & & & $1: 0: 0$ & -.. & --- \\
\hline $88 \mathrm{~K} 3.46 \times 88 \mathrm{~K} 1.3$ & $\mathrm{BC}_{1} \# 9$ & OrOr $\times y y$ & 55 & & & $1: 0: 0$ & $\cdots$ & -.. \\
\hline \multicolumn{9}{|c|}{ Solanum stenotomum $\mathrm{x}$ phureja germplasm } \\
\hline 85D4 (open-pollinated) & & & 52 & 110 & 4 & & & \\
\hline 85D6 (open-pollinated) & & & 44 & 159 & 4 & & & \\
\hline
\end{tabular}


Table 3. Absorbance maxima, retention times, and identification of carotenoid components in orange flesh tuber separated and collected with reverse-phase HPLC.

\begin{tabular}{lcccc}
\hline \hline \multicolumn{3}{c}{ Absorbance maxima (nm) } & & \\
\cline { 1 - 3 } & Solvents & Retention time & \\
\hline Hexane & Ethanol & Chloroform & (min) & Identity \\
\hline 422445473 & 424446473 & 432456485 & 6.6 & Lutein \\
451478 & 451478 & 462490 & 7.1 & Zeaxanthin \\
403427453 & 403427453 & 414436463 & 5.9 & Citroxanthin or \\
& & & & mutatochrome \\
& & & & \\
\hline
\end{tabular}

Table 4. Lutein and zeaxanthin content in A7411-2 (white flesh), W5335.3 (yellow flesh), and orange and white flesh segregants.

\begin{tabular}{|c|c|c|c|}
\hline Flesh type & Code & $\begin{array}{c}\text { Lutein } \\
\mu \mathrm{g} / 100 \mathrm{~g} \text { fresh wt }\end{array}$ & $\begin{array}{c}\text { Zeaxanthin } \\
\text { ug/ } 100 \mathrm{~g} \text { fresh wt }\end{array}$ \\
\hline White standard & A7411.2 & $65 \pm 9$ & $\mathrm{NF}^{2}$ \\
\hline Yellow standard & W5335.7 & $140 \pm 34$ & NF \\
\hline Orange parent & D6.11 & $120 \pm 12$ & $2055 \pm 257$ \\
\hline \multirow{3}{*}{ Orange $\mathrm{BC}_{1}$ segregant } & $90 \mathrm{~B} 10.2$ & $148 \pm 15$ & $1325 \pm 218$ \\
\hline & $90 \mathrm{~B} 10.20$ & $141 \pm 41$ & $1761 \pm 236$ \\
\hline & $90 \mathrm{~B} 10.32$ & $148 \pm 7$ & $1242 \pm 194$ \\
\hline Mean of orange $\mathrm{BC}_{1}$ segregants & & $146 \pm 11$ & $1426 \pm 138$ \\
\hline \multirow[t]{4}{*}{ White $\mathrm{BC}_{1}$ segregant } & $90 \mathrm{~B} 10.4$ & $142 \pm 9$ & $264 \pm 13$ \\
\hline & $90 \mathrm{~B} 10.6$ & $164 \pm 34$ & $388 \pm 120$ \\
\hline & $90 \mathrm{~B} 10.11$ & $98 \pm 6$ & $354 \pm 32$ \\
\hline & $90 \mathrm{~B} 10.24$ & $181 \pm 27$ & $207 \pm 15$ \\
\hline Mean of white $B C_{1}$ segregants & & $146=14$ & $304 \pm 27$ \\
\hline
\end{tabular}

${ }^{2} \mathrm{NF}=$ Not found.

The source germplasm of orange flesh, D6.11, contains large amounts of zeaxanthin (Fig. 2a). Zeaxanthin was not present in W5335.7 (Fig. 2b). Three unidentified xanthophylls were also found. Figure $2 \mathrm{c}$ shows a backcross segregant with orange flesh and Fig. 2d a white flesh segregant. Both segregants have zeaxanthin and lutein present, but the quantity of zeaxanthin in the orange flesh type is much greater. The presence of zeaxanthin in white flesh is apparently related to the genetic background of this cross, as zeaxanthin has not been noted in other white flesh material of different genetic origin or in the yellow flesh W5335.7.

Quantitation of carotenoids. Xanthophyll content of various clones was determined from freshly harvested tubers, but only zeaxanthin and lutein contents are given (Table 4). A one-way analysis of variance (ANOVA) failed to find significant differences between clones in lutein content $\left(\mathrm{F}_{(7,1)}=1.4\right.$, nonsignificant $)$. In sharp contrast, the mean zeaxanthin content of orange flesh genotypes is more than five times greater than that of the white flesh genotypes. The ANOVA for zeaxanthin confirmed significant differences between clones and an orthogonal comparison of orange vs. white flesh types was highly significant $(\mathrm{F}(1,10)=$ 108.2, $P<0.001)$.

\section{Discussion}

Zeaxanthin was not detected in the yellow flesh parent nor in the white flesh tetraploid clone A7411.2. Within the segregating progeny, however, it appeared that the genetic background allowed synthesis of zeaxanthin in amounts that did not cause the flesh to appear orange in the absence of the Or allele. The main effect of the putative $O r$ allele appears to be synthesis of large amounts of zeaxanthin. Since the total amount of zeaxanthin and lutein is much higher in the orange flesh types, this suggests that the effect of the Or allele is to promote greater synthesis of zeaxanthin and is not simply conversion of lutein to zeaxanthin. The yellow flesh clone analyzed in this study, W5337.3, had a lutein content of 140 $\mu \mathrm{g} / 100 \mathrm{~g}$ fresh weight, which is within the range of the yellow flesh European varieties. In contrast, the lutein + zeaxanthin content of the orange flesh genotypes described here was four to five times greater than the highest total xanthophyll content of these European varieties (Iwanzik et al., 1983).

Simon and Wolff (1987) reported that the concentration of carotenoids in carrot (Daucus carota L.) genotypes differs widely. These authors noted that carotenoid level in "normal" carrot was $\approx 10,000 \mu \mathrm{g} / 100 \mathrm{~g}$ fresh weight, more than six times higher than that reported here for orange flesh potato. Carrot carotenoids consist primarily of the hydrocarbon carotenes alpha- and betacarotene, whereas the primary constituents of the potato tuber flesh are xanthophylls. Hydrocarbon carotenes have either not been found or have been detected in trace amounts in potato (Bergthaller et al., 1986; Brunstetter and Wiseman, 1947; Caldwell et al., 1945; Iwanzik et al., 1983; Pendlington et al., 1965; Tevini et al., 1984; Woolfe, 1987).

The carotenoid contents described here are the highest to date reported for cultivated Solanum potato. The significance for human nutrition is not clear, as lutein and zeaxanthin have no provitamin A activity (Bauernfeind et al., 1981). Furthermore, orange flesh may have marketing value as a novel feature in homecooked or industrially processed potato-based food items. 

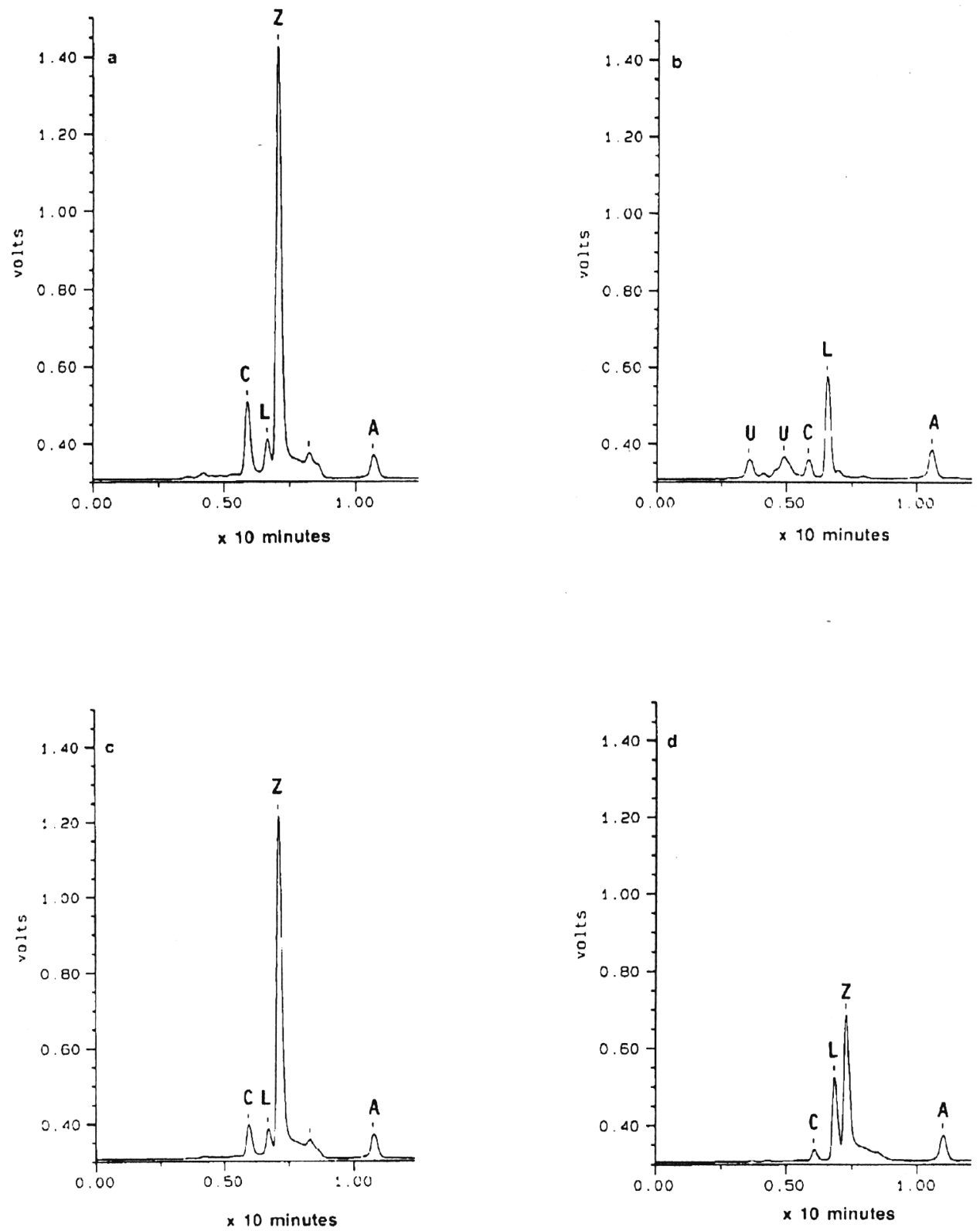

Fig. 2. Chromatograms of xanthophylls in orange, yellow, and whitc flesh potatoes: (a) D6.11 (orange), Ory; (b) W5335.7 (yellow), Yy; (c) orangc flesh backcross segregant from $\mathrm{BC}_{1} \# 4$, Ory; (d) white flesh backcross segregant from $\mathrm{BC}_{1} \# 4, y y . \mathrm{L}=$ lutein, $\mathrm{Z}=$ zeaxanthin, $\mathrm{A}=$ Beta-Apo- $8^{-}$-carotenal (internal standard), $\mathrm{C}=$ citroxanthin or mutatochrome, $U=$ unknown.

This is the first report of genetic control of orange flesh in potato. An allele at the $Y$ locus, denoted $O r$, appears to control increased content of zeaxanthin. This allele appears to be dominant to $y$ and $Y$, which control white and yellow pigmentation, respectively, at this locus. Thus, this trait, which is easily scored visually in tubers, may be added as a monogenic morphological marker available for genetic studies.

\section{Literature Cited}

Bauernfeind, J.C., C.R. Adams, and W.L. Marusich. 1981. Carotenes and other vitamin A precursors in animal feed, p. 563-743. In: J.C. Bauernfeind (ed.). Carotenoids as colorants and vitamin A precursors. Academic Press, New York.

Bergthaller, W., G. Tegge, and W. Hoffmann. 1986. Effect of storage temperature on color changes and content of carotenoids of dehydrated diced potatoes, p. 456-475. In: B.F. Cargill (ed.). Engineering of potatoes program. Michigan State Univ., East Lansing, and Amer. Soc. Agr. Eng.

Bonierbale, M.W., R.L. Plaisted, and S.D. Tanksley. 1988. RFLP maps based on a common set of clones reveal modes of chromosomal evolution in potato and tomato. Genetics 120:1095-1103.

Brunstetter, B.C. and H.G. Wiseman. 1947. Carotenoid pigments in tubers of the Katahdin variety of Irish potatoes. Plant Physiol. 22:421-437.

Caldwell, J.S., B.C. Brunstetter, C.W. Culpepper, and B.D. Ezell. 1945. Causes and control of discoloration in dehydration of white potatoes. The Canner 100:35-39,112-122.

De Ritter, E. and A.E. Purcell. 1981. Carotenoid analytical methods, p. 815-923. In: J.C. Bauernfeind (ed.). Carotenoids as colorants and vitamin precursors. Academic Press, New York.

Fruwirth, C. 1912. Zur Züchtung der Kartoffel. Dtsch. Landw. Presse 39:551-552,565-567. 
Hanneman, R.E., Jr., and J.B. Bamberg. 1986. Inventory of tuber-bearing So/unum species. Wisconsin Agr. Expt. Sta. Res. Bul. 533.

Howard, H.W. 1970. Fertility and sterility problems, p. 20-23. Genetics of the potato. Logo Press, London.

Hunter, R.S. 1942. Photoelectric tristimulus calorimetry with three filters. U.S. Natl. Bur. Stnd. Circ. C-429, Washington, D.C.

Iwanzik, W., M. Tevini, R. Stute, and R. Hilbert. 1983. Carotinoidgehalt und- Zusammensetzung verschiedener deutscher Kartoffelsorten und deren Bedeutung für die Fleischfarbe der Knolle. Potato Res. 26:149162 .

O'Connor, K. 1990. Non-aqueous reverse phase purification of carotenes using a small particle preparative packing. Waters Column Summer, p. 1-2,11-13.

Peloquin, S.J. 1982. Meiotic mutants in potato breeding. Stadler Symp. Univ. of Missouri, Columbia. 14:99-109.

Pendlington, S., M.S. DuPont, and F.J. Trussell. 1965. The carotenoid pigments of $S$. tuberosum. Proc. Biochem. Soc. p. 25-26.
Rivas, J. de las, A. Abadia, and J. Abadia. 1989. A new reversed phaseHPLC method resolving all major higher plant photosynthetic pigments. Plant Physiol. 91:190-192.

Siebenick, H. 1959. Beobachtungen an der Fleischfarbe der rohen Kartoffel. European Potato J. 2:229-236.

Schick, R. 1956. Methoden und Probleme der Kartoffelzüchtung. Zber. dtsch. Akad. Land Wiss. Berl. 5(29):1-40.

Simon, P.W. and X.Y. Wolff. 1987. Carotenes in typical and dark orange carrots. J. Agr. Food Chem. 35:1017-1022.

Singh, U. and J.H. Bradbury. 1988. HPLC determination of vitamin A and vitamin $\mathrm{D}_{2}$ in South Pacific root crops. J. Sci. Food Agr. 45:87-94.

Tevini, M., W. Iwanzik, and G. Schoneker. 1984. Analyse, Vorkommen und Verhalten von Carotinoiden in Kartoffeln und Kartoffelprodukten, p. 36-53. Jahrbuch 1984, Forschungskreis der Ernährungsindustrie e.V., Hannover.

Woolfe, J.A. 1987. Potato in the human diet. Cambridge Univ. Press, Cambridge, U.K. 